SCIREA Journal of Clinical Medicine

ISSN: 2706-8870

http://www.scirea.org/journal/CM

August 12, 2021

SCIREA

Volume 6, Issue 4, August 2021

\title{
The Relationship between Emotional Intelligence and Non-cognitive Factors in Dental Students
}

\author{
Natalie Wen ${ }^{1 *}$, Muath Aldosari ${ }^{2}$, Sang E. Park ${ }^{3}$ \\ ${ }^{1}$ Natalie L. Wen, B.A., DMD candidate, Class of 2022, Harvard School of Dental Medicine \\ ${ }^{2}$ Muath A. Aldosari, BDS, MPH, DMSc, Assistant Professor at the Department of \\ Periodontics and Community Dentistry, College of Dentistry, King Saud University, Riyadh, \\ Kingdom of Saudi Arabia. Lecturer at the Department of Oral Health Policy and \\ Epidemiology, Harvard School of Dental Medicine, Boston, MA, United States of America \\ ${ }^{3}$ Sang E. Park, DDS, MMSc, Associate Dean for Dental Education, Office of Dental \\ Education, Harvard School of Dental Medicine
}

\begin{abstract}
The aim of the study was to evaluate the association between emotional intelligence (EI) and the non-cognitive components of student data, such as age, gender, gap year prior to starting dental school, and number of adversities experienced in life. A validated EI questionnaire was sent to the dental students from the graduation classes of 2021 through 2024 in the predoctoral program at Harvard School of Dental Medicine (HSDM). Self-reported demographic and non-cognitive student data on age, gender, and number of gap years, and whether the student experienced adversities in life were obtained. Bivariate analyses were performed to evaluate associations between self-reported EI score and the non-cognitive student data. Seventy (48.6\%) DMD students consented to filling out a self-rated EI survey; $64.3 \%$ of them were females. Age was found to be statistically associated $(p<0.05)$ with
\end{abstract}


social awareness score. Male gender was found to be statistically associated with relationship management score. No statistical association was found between total EI score and age, gender, nor number of gap year. Interestingly, the strongest correlation was found between EI score and gap year $(\mathrm{r}=0.12)$. Additionally, students age 26 and above reported higher EI scores compared to younger students. Non-cognitive student factors, such as age, gender, gap year, and life adversities, did not show statistically significant correlation in relation to emotional intelligence in the cohort of the study. These results suggest that although the noncognitive student data can serve as an important resource in student selection and performance, further studies are needed to better understand their association with the level of emotional intelligence.

KEYWORDS: Emotional intelligence, Admissions, Predoctoral dental program, Noncognitive student data

\section{INTRODUCTION}

Emotional intelligence (EI) is defined as a person's ability to perceive, regulate and respond to his or her emotions as well as the emotions of another individual or collective group within specific contexts or environments. ${ }^{1-2}$ The concept of EI gained popularity in the late 90's, when EI was broken down into Trait EI and Ability EI. ${ }^{3-5}$ Ability EI refers to how one uses perceived emotions to guide thought and intercommunication, and is particularly important in the health professions where the ability to read patients' emotions significantly improves communication and builds trust between the professional and the patient. Since the dentist has the unique opportunity to diagnose, plan, perform and monitor the entire treatment process, EI is essential for strengthening the dentist-patient relationship and ensuring patient compliance.

It has been argued that while EI is important for building rapport and demonstrating empathy towards the patient, what ultimately matters for more complex cases and in stressful situations is problem-solving and critical thinking, both of which are measured by intelligence. ${ }^{6}$ However, studies have revealed the significant consequences of undermining the importance of EI. For example, Munk used the Commission on Dental Accreditation (CODA) standards of cognitive, technical and emotional intelligences to measure the proportion of infarctions across the U.S. that were related to EI. ${ }^{7}$ 
Interestingly, $56.6 \%$ of 1,100 infarction cases reported were EI related. Munk emphasized four subcategories of EI to focus on: transparency, teamwork and collaboration, organizational awareness and accurate self-assessment, all of which can be taught during dental school when individuals develop their professional identities. Moreover, Shouhed et. al. found that patients with more complicated medical conditions increases the risk of malpractice and that resident physicians scored lower in social awareness and adaptability, suggesting the need to provide EI training earlier with more foundational patient cases. ${ }^{8} \mathrm{EI}$ has also been found to play an important role in patient relationship management. ${ }^{9}$

Price and Park looked at the noncognitive components of admissions data, e.g. interview score, to evaluate if qualities such as personality predict success during the pre-doctoral curriculum and residency program placement. ${ }^{10}$ The study found that interview performance had no significant association with pre-doctoral performance. It is logical to expect personality to influence a student's feeling of belonging and success at a specific school, yet the findings of this study suggest that the current interview process does not sufficiently measure personality and EI. In fact, previous studies argue that there is an overlap of EI and personality but the two should be measured separately. ${ }^{11}$

Perhaps the lack of association between interview score and pre-doctoral performance is due to insufficient distinction of EI from personality and/or insufficient understanding of how personality influences EI. Gardner and Dunkin studied the relationship between personality, EI and situational judgment tests and surgical residency performance. Only Step 1 and situation judgement test scores were associated with residency performance 1 year later. ${ }^{12}$ This suggests the importance of cultivating emotional competencies during pre-doctoral training to prepare students to make critical decisions during different clinical scenarios.

Studies have shown that EI training program results vary based on the population studied. The further along in training one is when they start, the less change in EI is observed. ${ }^{13}$ Thus, education on EI may be more impactful earlier in the professional's education such as during dental school or other health professional schools. Further research needs to be conducted that can contribute information to improving our understanding of potential factors associated with emotional intelligence in dental education and shed light on the importance of incorporating and measuring EI skills among dental students. The aim of this study was to evaluate any differences in EI that may exist among dental students based on the selfreported non-cognitive admissions data including age, gender, number of gap year and number of adversities experienced in life. 


\section{MATERIALS AND METHODS}

The Harvard School of Dental Medicine and Harvard Medical School Institutional Review Board for the Faculty of Medicine approved the study [IRB 19-2030]. The survey consisted of a validated emotional intelligence questionnaire consisting of demographic and noncognitive questions and emotional intelligence questions based on questions from the 2002 study by Wong and Law and Mind Tools. ${ }^{14}$ Questions for each type of emotional competency as described by Goleman in areas of self-awareness, self-regulation, social awareness, and relationship management were included. ${ }^{5}$ Some questions belonged to more than one emotional competency category. Additional questions on types of adversities experienced and utilization of preferred wellness resources were included at the end of the survey. A total of 144 students from the DMD graduation classes of 2021 through 2024 were recruited by email containing a Qualtrics (Qualtrics, Provo, UT) survey link. All responses were anonymous, and two reminder emails were sent.

EI score was calculated based on the Likert Scale, with a score of 1 corresponding to strongly disagreeing with a positive or neutral statement (e.g. "I have a good understanding of my own emotions"; "I must hide my negative feelings to perform my job well") and a score of 5 corresponding to strongly agreeing with a positive or neutral statement (e.g. "I set long term goals and review my progress regularly"). Therefore, with 13 EI-based questions, EI score may range between 13 and 75 .

Descriptive analysis was used to report the characteristics, with the mean EI score and standard deviation (SD), of participating students. Correlation between students' characteristics and total EI score as well as each EI domain score was assessed using Pearson's coefficients. Then, Bivariate regression analyses were performed to evaluate the crude associations between self-reported total EI score/EI domain score and age group, gender, whether the student took one or more gap years, and number of adversities experienced in life. Lastly, we conducted a multiple linear regression model to assess the adjusted association with the average EI and EI domain scores, controlling for students' characteristics. We reported the average difference in EI score with the corresponding 95\% confidence intervals $(95 \% \mathrm{CI})$. Any differences with $\mathrm{p}<0.05$ was considered statistically significant, and all statistical analyses were performed using Stata/SE Version 16.1 (StataCorp, College Station, TX). 


\section{RESULTS}

Of 144 predoctoral students in the predoctoral program, a total of 70 students responded to the survey resulting in $48.6 \%$ of the sampled students. There were 45 female respondents $(64.3 \%)$ and 25 male respondents $(35.7 \%)$ (Table 1). The majority of the respondents were between 23-25 years of age, and 24.3\% took at least one gap year; $17.7 \%$ of them took two gap years.

Table 1. Descriptive characteristics of students who completed the emotional intelligence survey

\begin{tabular}{|c|c|c|}
\hline & Frequency & Percentage \\
\hline Overall & 70 & $100 \%$ \\
\hline \multicolumn{3}{|l|}{$\overline{\text { Age }}$} \\
\hline $20-22$ & 17 & $24.3 \%$ \\
\hline $23-25$ & 46 & $65.7 \%$ \\
\hline $26+$ & 7 & $7 \%$ \\
\hline \multicolumn{3}{|l|}{ Gender } \\
\hline Female & 45 & 64.3 \\
\hline Male & 25 & 35.7 \\
\hline \multicolumn{3}{|c|}{ Took a gap year } \\
\hline No & 53 & $75.7 \%$ \\
\hline Yes & 17 & $24.3 \%$ \\
\hline \multicolumn{3}{|c|}{ Number of adversities experienced in life } \\
\hline 1 & 19 & $24.1 \%$ \\
\hline 2 & 15 & $21.4 \%$ \\
\hline 3 & 17 & $24.3 \%$ \\
\hline $4+$ & 19 & $27.1 \%$ \\
\hline
\end{tabular}




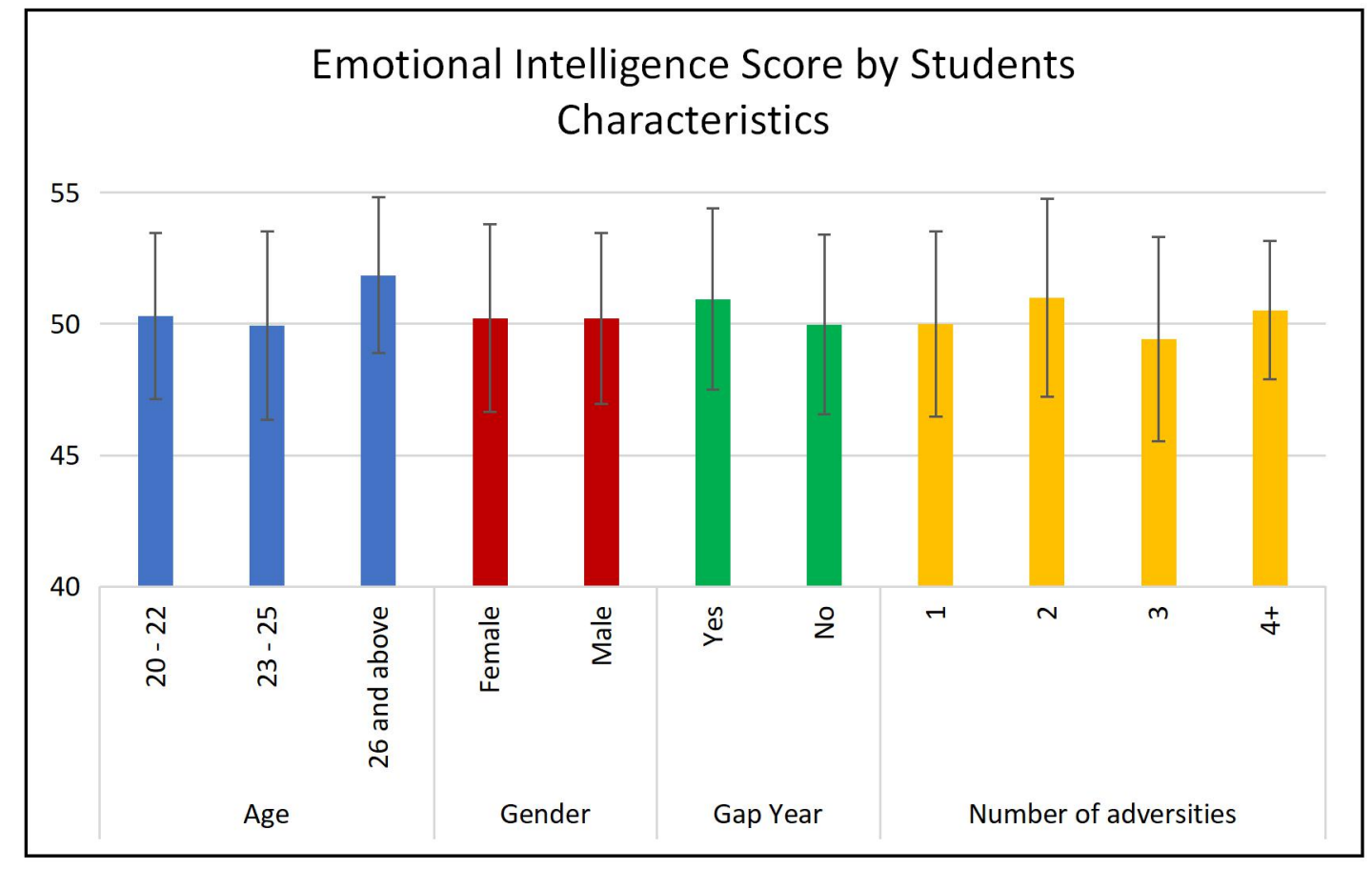

Figure 1. Distribution of Students' Emotional Intelligence Scores

The mean EI score among survey respondents was 50.21 with standard deviation of 3.43. Figure 1 depicts the distribution of EI scores. Descriptive statistics were calculated to provide a general description of the sample including number of respondents in each gender and age category, percentage of respondents who took at least one gap year, range of EI scores, and mean EI score. Pearson's coefficients between total EI score and students' characteristics indicated a weak correlation, with no factor being significantly correlated with EI score at $\mathrm{p} \leq 0.05$ (Table 2). However, social awareness score was significantly correlated with age $(\mathrm{r}=0.245)$, and relationship management was significantly correlated with male gender $(\mathrm{r}=0.291)$. Total EI score was negatively correlated with gender and positively correlated with increasing age, increasing number of adversities experienced, and gap year. The strongest correlation was between total EI score and gap year $(r=0.12)$ where gap year was positively associated with total EI score. 
Table 2. Pairwise Pearson's correlation coefficients between students' characteristics and each domain with the emotional intelligence score (Statistically significant at $\mathrm{p}<0.05$ )

\begin{tabular}{|c|c|c|c|c|c|}
\hline & \multirow[b]{2}{*}{$\begin{array}{l}\text { Emotional } \\
\text { intelligence }\end{array}$} & \multicolumn{4}{|c|}{ Students' Characteristics } \\
\hline & & Age groups & Gender & $\begin{array}{l}\text { Taking a gap } \\
\text { year }\end{array}$ & $\begin{array}{l}\text { Adversities } \\
\text { experienced } \\
\text { in life }\end{array}$ \\
\hline Emotional intelligence & -- & 0.075 & -0.003 & 0.121 & 0.008 \\
\hline Self-awareness & $0.480 *$ & $0.245^{*}$ & -0.060 & 0.030 & -0.112 \\
\hline Self-management & $0.623 *$ & -0.038 & 0.008 & 0.088 & 0.011 \\
\hline Social awareness & $0.606^{*}$ & 0.075 & -0.189 & 0.133 & 0.052 \\
\hline Relationship management & $0.595^{*}$ & 0.096 & $0.291 *$ & -0.056 & -0.120 \\
\hline
\end{tabular}

Linear regression analysis was performed comparing differences in EI scores based on age, gender, number of gap years, and number of adversities (Table 3). Overall, students' characteristics were not associated with EI score, even after controlling for the measured characteristics. Age groups of comparison included students of 20-22 years of age, 23-25 years of age and 26 and above years of age. Students ages 26 and above had 1.35 higher EI score compared to dental students between 20 and 22 years old $(95 \% \mathrm{CI}=-1.98,4.69)$. Students who took at least one gap year had 1.10 higher EI score compared to those who did not $(95 \% \mathrm{CI}=-1.03,3.23)$. Students who experienced two adversities had the highest EI scores compared to those who reported experiencing only one adversity in life (Average difference: $1.11 ; 95 \% \mathrm{CI}=-1.32,3.54)$.

Table 3. Linear regressions of the associations of students' characteristics with mean emotional intelligence score

\begin{tabular}{|c|c|c|c|}
\hline Students' characteristics & $\begin{array}{l}\text { Average emotional } \\
\text { intelligence score } \\
(\text { Mean } \pm \text { SD*) }\end{array}$ & $\begin{array}{l}\text { Crude difference in emotional } \\
\text { intelligence } \\
(95 \% \mathrm{CI})^{\dagger}\end{array}$ & $\begin{array}{l}\text { Adjusted }^{\mathrm{S}} \text { difference in } \\
\text { emotional intelligence score } \\
(95 \% \mathrm{CI})\end{array}$ \\
\hline \multicolumn{4}{|l|}{ Age } \\
\hline $20-22$ & $50.29 \pm 3.16$ & $\operatorname{Ref}^{t}$ & $\operatorname{Ref}^{\ddagger}$ \\
\hline $23-25$ & $49.93 \pm 3.59$ & $-0.36(-2.31,1.56)$ & $-0.30(-2.39,1.79)$ \\
\hline $26+$ & $51.86 \pm 2.97$ & $1.56(-1.52,4.64)$ & $1.35(-1.98,4.69)$ \\
\hline \multicolumn{4}{|l|}{ Gender } \\
\hline Females & $50.22 \pm 3.57$ & Ref $^{\star}$ & $\operatorname{Ref}^{\ddagger}$ \\
\hline Males & $50.20 \pm 3.25$ & $0.02(-1.70,1.74)$ & $0.28(-1.54,2.11)$ \\
\hline
\end{tabular}




\begin{tabular}{|c|c|c|c|}
\hline \multicolumn{4}{|c|}{ Took a gap year } \\
\hline No & $49.98 \pm 3.43$ & $\operatorname{Ref}^{\ddagger}$ & $\operatorname{Ref}^{\ddagger}$ \\
\hline Yes & $50.94 \pm 3.45$ & $0.96(-0.95,2.87)$ & $1.10(-1.03,3.23)$ \\
\hline \multicolumn{4}{|c|}{ Number of adversities experienced in life } \\
\hline 1 & $50.00 \pm 3.53$ & $\operatorname{Ref}^{\ddagger}$ & $\operatorname{Ref}^{\ddagger}$ \\
\hline 2 & $51.00 \pm 3.78$ & $1.00(-1.39,3.39)$ & $1.11(-1.32,3.54)$ \\
\hline 3 & $49.41 \pm 3.89$ & $-0.59(-2.90,1.72)$ & $-0.84(-3.23,1.54)$ \\
\hline $4+$ & $50.53 \pm 2.63$ & $0.53(-1.72,2.77)$ & $0.44(-1.92,2.79)$ \\
\hline
\end{tabular}

A similar linear regression analysis was performed using EI domain scores (Table 4). Age was found to be statistically associated with social awareness, and male gender was statistically associated with relationship management. Students ages 26 and above scored higher in social awareness compared to students ages 20-22 (Average difference: 1.22; $95 \% \mathrm{CI}=0.13,2.31)$. Male respondents scored higher in relationship management compared to female respondents (Average difference: $1.02 ; 95 \% \mathrm{CI}=0.21,1.83$ ).

Table 4. Linear regressions of the associations of students' characteristics with mean score of each domain for emotional intelligence

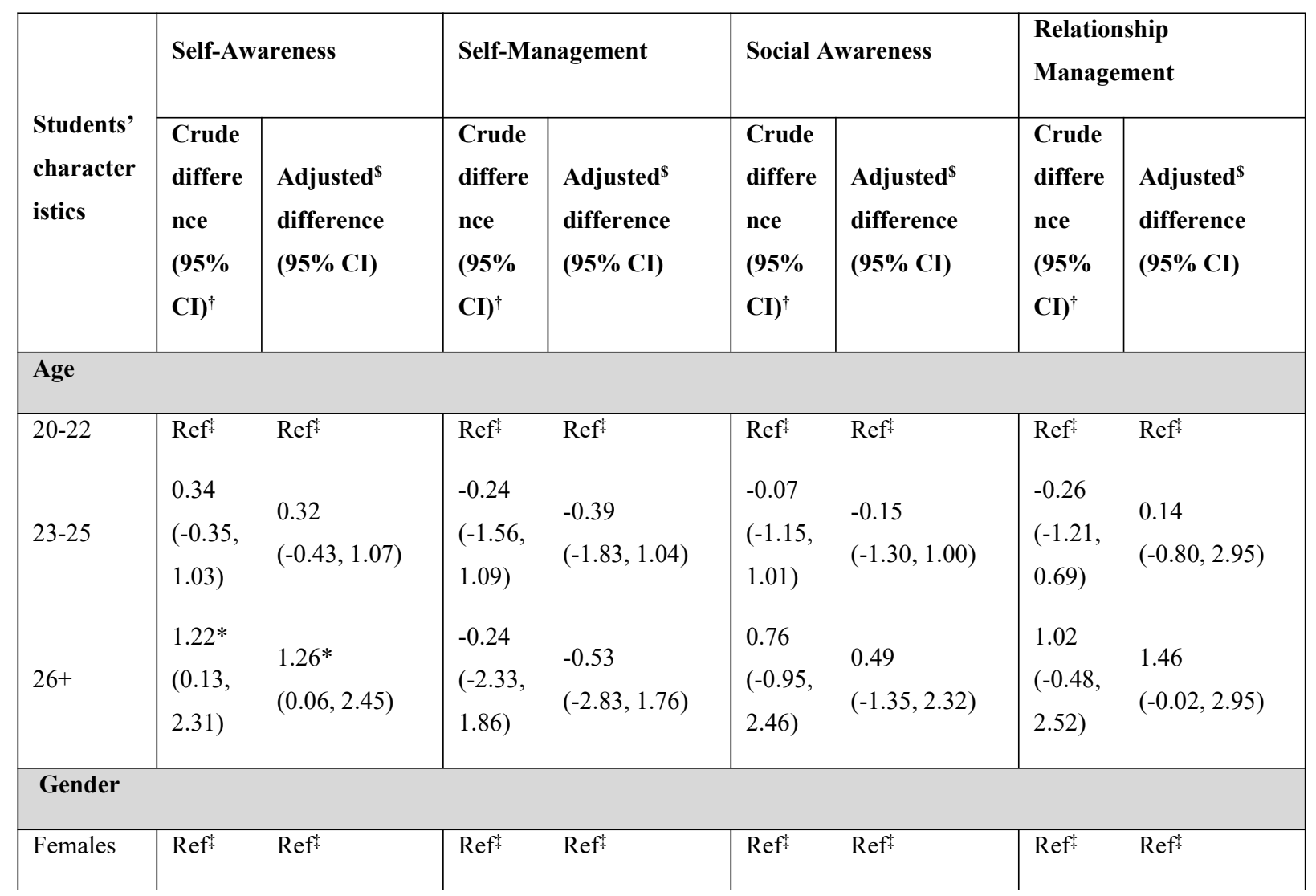




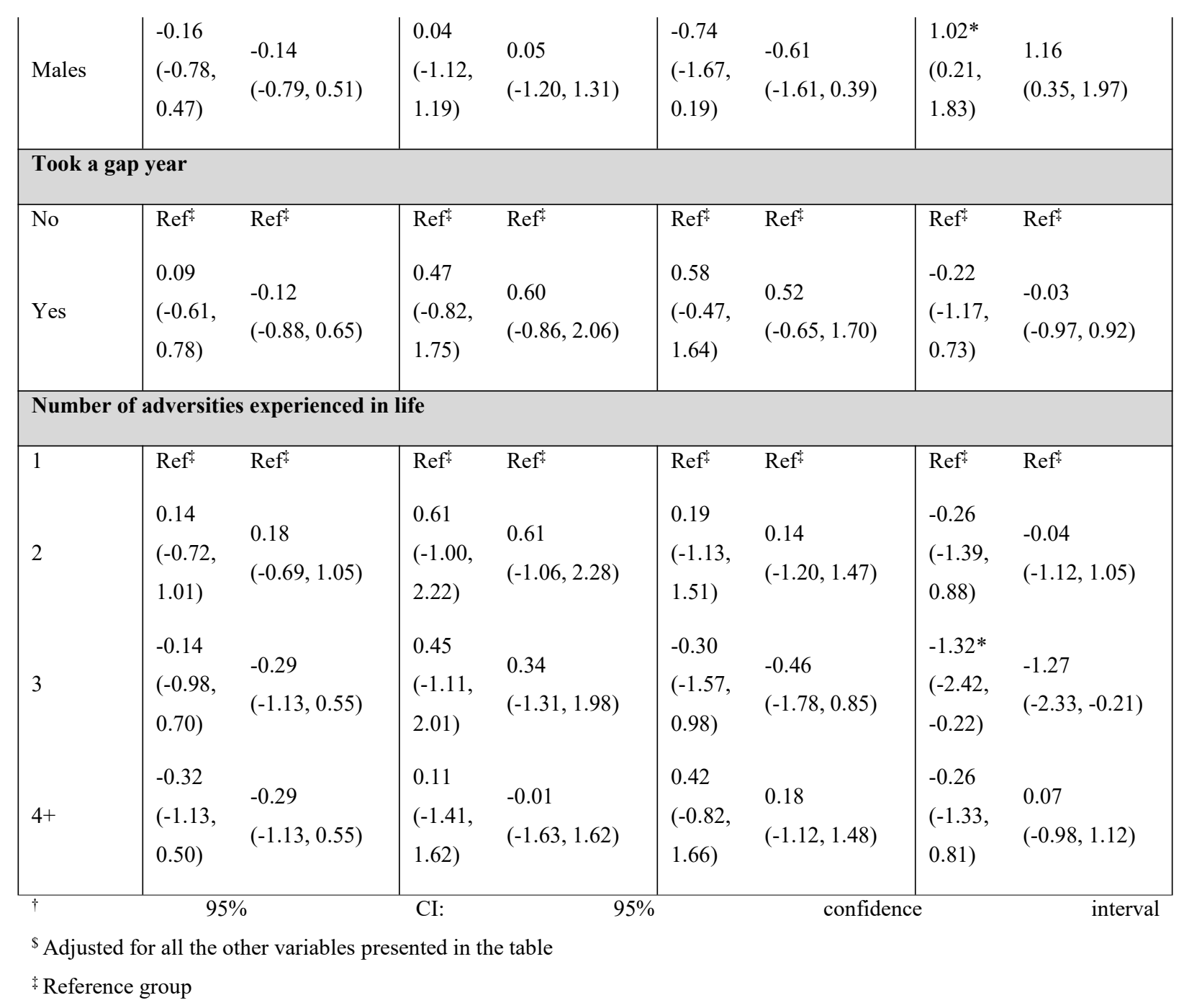

\section{DISCUSSION}

Emotional intelligence can be fostered by developing certain emotional competencies that are divided into personal and social competencies including self-awareness, self-regulation, selfmotivation, social awareness, and social skills. ${ }^{15-16}$ Partido and Stefanik reported significant improvements in EI scores after dental students took an EI training course. ${ }^{17}$ Moreover, Farah-Franco et. al. found that self-actualization and happiness, which are measures of EI, were significantly associated with level of professionalism among dental students. ${ }^{18}$ It is understood that professionalism is a crucial component for successful peer, faculty, and patient communication and relationship management during and after dental school. ${ }^{19}$ The classification of emotional competencies suggests that these skills are cultivable during dental school training. 
Students are encouraged and required to reflect on their professional and clinical growth throughout their training, and it is expected that students are competent professionals at graduation. Consequently, EI level should increase with year in training. In the current study, age was found to be positively correlated with social awareness. This may be due to longer time spent interacting with patients, although respondents were not grouped by class year. Moreover, although not statistically significant, total EI score was positively correlated with age. Future studies investigating the relationship between age, class year, and EI can help elucidate how dental education chronologically influences EI. Future professionalism index measures may also be useful for selecting dental and residency program applicants in order to better understand the types of support systems students need to develop emotional competencies and professional behavior during their training. ${ }^{20}$

The current study was an initial step to identify any associations between self-reported EI and gender, age, number of gap year(s) taken, and number of adversities experienced. Previous studies have shown that the number of female applicants to dental schools have surpassed male applicants and that age affects performance on standardized exams and during residency, influencing our decision to study how these factors are related to EI level. ${ }^{21-23}$ The hypothesis was that applicants who took one or more gap years would self-report higher EI levels due to additional time available for self-exploration, reflection, and growth.

Interestingly, the current study found male gender to be significantly associated with relationship management. Components of relationship management may include collaboration, teamwork, and learning from others. Future studies exploring how EI or communication skill courses during dental school affect students' EI level may provide information on how to support students in managing their professional relationships.

Partido and Stafford measured self-reported EI score among dental hygiene students and found EI score to be statistically higher in females than males. Standard deviation of total EI score distribution was about 9 points. ${ }^{24}$ Interestingly, our study found no significant difference in EI scores based on gender, with a narrower distribution of EI scores. Larger studies may help identify baseline EI level of students and explore any demographic characteristic(s) that may be associated with lower EI score.

Gap year was found to have the strongest correlation with EI score $(r=0.12)$ in the study. It is possible that because of their older age, students who took one or more gap years enter dental school with a higher baseline EI level. What students decide to pursue during their gap 
year(s) varies, with some examples including traveling, research, obtaining another degree, starting a family, and employment. However, there is insufficient research on the relation between type of gap year activity and cognitive and non-cognitive dental school admission factors.

In a study related to medical school burnout, Guang et. al. found that students taking one or more gap years experienced significantly lower levels of burnout. ${ }^{25}$ Sidiqi et. al. reported producing more publications as the main reason medical students took a gap year before applying to radiation oncology residency programs. ${ }^{26}$ Activities such as advanced education or employment may contribute to improving the self-regulation and self-actualization aspects of EI. The stress of balancing classroom workload, preclinical training, and clinical responsibilities can lead to burnout among dental students as well. It would be useful to further study the association between type of gap year activity and EI level.

An analysis of the data showed that students 26 years and older had higher EI scores compared with other age groups. Age has been shown to be positively associated with multiple mini-interview (MMI) and traditional interview performance as well as certain situational judgement scenarios. ${ }^{27-28}$ This is likely due to the fact that chronologically mature students may have more life experience and previous interview opportunities. Interview questions and situational judgement scenarios could be created to better understand thought processes of this group of students. Studies measuring the EI level of older students, such as the starting age of 26 years or older, throughout dental school may also identify differences in baseline EI levels based on age. Comparing EI levels among students of the same age but different class year with dental school performance measures may also help better understand the role of certain curriculum components in improving EI and professionalism.

The cost of applying to dental schools is multi-faceted and presents several barriers that may deter financially disadvantaged and underrepresented minority (URM) students and those from diverse backgrounds from applying. ${ }^{29}$ Experiencing adversities can profoundly affect a student's sense of self, motivation, and relationship management. ${ }^{30-31}$ Besides augmenting their applications, dental school applicants may take one or more gap years to prepare financially. During their gap year(s) students may also experience other personal, familial, or academic challenges. Our study found that $97 \%$ of survey respondents experienced one or more adversities. Future studies Investigating the effect of type of adversity on baseline EI level when entering dental school can provide insight on how past experiences shape an applicant's EI profile. 
The ability to regulate one's own emotions and effectively communicate with colleagues and patients during uncertain situations impacts the amount of stress a student feels while adapting to the clinical environment. Ballard et. al. reported limited association of cognitive admission criteria and success in dental school, suggesting that non-cognitive components such as personality, emotional intelligence, and resiliency may play a larger role in helping students develop professional identities. ${ }^{32}$ Pau et. al. reported EI was inversely associated with perceived stress levels and stress levels were higher among younger students, females, and those in higher years of study. ${ }^{33}$ Studies comparing EI level across class year may further provide insight on which parts of a curriculum are particularly challenging.

Future studies investigating the EI levels and stress-coping mechanisms of older students may be useful. Peer-to-peer mentorship programs such as Big and Little Sibling Pairings can serve as an extracurricular method for training emotional competencies in students. Training EI competencies early during dental school can also prepare students to interact with patients. ${ }^{34}$ The survey question in the study also indicated that counseling, nutrition workshops, and fitness classes were the top three resources that students expressed interest in for managing stress and emotional well-being. Providing a space for reflection during the busy school schedule may help students strengthen emotional competencies through more instant and relevant reflection of professional growth that the gap year does not provide.

The current study was limited by a relatively small sample size due to the small class size which limits the statistical power of our analyses. In addition, there was unequal number of respondents in each gender and age group category, which may have affected calculation and comparison of mean EI scores. Without surveying dental personnel past the typical age range of 21-28 years old predoctoral students, such as residents or faculty, the self-measured EI range is also limited in its comparative range. Moreover, students with lower EI score may have already been excluded after the admissions interview.

In addition, since this study was also conducted at a single dental school, results may not be generalizable to other dental school populations. EI was also measured using a self-reported EI questionnaire, creating possibility for different interpretations of questions and their relation to EI compared to empathy or general job performance. The number of questions for each category of EI was also limited in order to increase survey response. For example, further information gathered on adversities experienced and distribution of underrepresented minorities or socioeconomically disadvantaged students may reveal confounding factors. As part of future study, methods should include involving a larger dental student and advanced 
graduate student population and measurement of EI using more standardized scoring such as situational judgement criteria. These methods are needed to further understand factors affecting EI level and how EI level is associated with dental school education.

\section{CONCLUSION}

The non-cognitive student factors may contribute to better understanding of possible connection with emotional intelligence although no statistical association between selfreported EI and age, gender, number of gap year, nor number of adversities were found in the cohort of the study. Adversities experienced prior to and during dental school continue to influence how dental students navigate through unfamiliar clinical environments. Additional measures exploring previous life experiences of students who are chronologically mature and who took one or more gap years may provide more insight on EI levels and the role of emotional intelligence in dental education.

\section{REFERENCES}

[1] Law KS, Wong C-S, Song LJ. The construct and criterion validity of emotional intelligence and its potential utility for management studies. J Appl Psych. 2004;89(3):483-49

[2] Wong C-S, Law KS. The effects of leader and follower emotional intelligence on performance and attitude: An exploratory study. The Leadership Quarterly. 2002;13(3):243-274.

[3] Petrides K, Furnham A. Trait emotional intelligence: psychometric investigation with reference to established trait taxonomies. Eur J Pers. 2001;15:425-448.

[4] Salovey P, Mayer JD. Emotional intelligence. Imagin Cogn Pers. 1990;9(3):185-211.

[5] Goleman, Daniel \& Boyatzis, Richard \& McKee, Annie. (2002). Primal Leadership: Realizing the Power of Emotional Intelligence.

[6] Willoughby E, Boutwell BB. Importance of intelligence and emotional intelligence for physicians. JAMA. 2018 Jul 10;320(2):205.

[7] Munk LK. Implications of state dental board disciplinary actions for teaching dental students about emotional intelligence. J Dent Educ. 2016 Jan;80(1):14-22. 
[8] Shouhed D, Beni C, Manguso N, IsHak WW, Gewertz BL. Association of emotional intelligence with malpractice claims: A Review. JAMA Surg. 2019 Mar 1;154(3):250256.

[9] Victoroff KZ, Boyatzis RE. What is the relationship between emotional intelligence and dental student clinical performance? J Dent Educ. 2013 Apr;77(4):416-26.

[10] Price MD, Park SE. Can noncognitive components of admissions data predict dental student performance and postdoctoral program placement? J Dent Educ. 2018 Oct;82(10):1051-1058.

[11] Grewal D, Davidson HA. Emotional intelligence and graduate medical education. JAMA. 2008 Sep 10;300(10):1200-2.

[12] Gardner AK, Dunkin BJ. Evaluation of validity evidence for personality, emotional intelligence, and situational judgment tests to identify successful residents. JAMA Surg. 2018 May 1;153(5):409-416.

[13] Dugan JW, Weatherly RA, Girod DA, Barber CE, Tsue TT. A longitudinal study of emotional intelligence training for otolaryngology residents and faculty. JAMA Otolaryngol Head Neck Surg. 2014 Aug;140(8):720-6.

[14] Ng KM, Wang C, Zalaquett CP et al. A confirmatory factor analysis of the Wong and Law Emotional Intelligence Scale in a sample of international college students. Int J Adv Counselling. 2007 Oct 16;173(29).

[15] Emotional Intelligence Consortium - Emotional Competence Framework. At: http://www.eiconsortium.org/reports/emotional_competence_framework.html Accessed: January 9, 2021.

[16] Goleman D. Working with Emotional Intelligence. New York: Bantam Dell, 1998.

[17] Partido, BB, Stefanik, D. Impact of emotional intelligence training in a communication and ethics course among second-year dental students. J Dent Educ. 2020;84:704-711.

[18] Farah-Franco S, Singer-Chang G, Deoghare H. Advancing the measurement of dental students' professionalism. J Dent Educ. 2017 Nov;81(11):1338-1344.

[19] Virtue SM, Pendergast L, Tellez M, Waldron E, Ismail A. Identifying noncognitive skills that contribute to dental students' success: dental faculty perspectives. J Dent Educ. 2017 Mar;81(3):300-309.

[20] Bajwa NM, Yudkowsky R, Belli D, Vu NV, Park YS. Improving the residency admissions process by integrating a professionalism assessment: a validity and feasibility study. Adv Health Sci Educ Theory Pract. 2017 Mar;22(1):69-89. 
[21] Slapar F, Cook BJ, Stewart D, Valachovic RW. U.S. dental school applicants and enrollees, 2017 entering class. J Dent Educ. 2018 Nov;82(11):1228-1238.

[22] DeSantis LL, Ghoneima A, John V, Eckert G, Stewart KT. Preliminary performance of the Advanced Dental Admission Test (ADAT): association between ADAT scores and other variables for applicants to residency programs at a U.S. dental school. J Dent Educ. 2018 Dec;82(12):1327-1334.

[23] Gallagher JE, Niven V, Donaldson N, Wilson NH. Widening access? Characteristics of applicants to medical and dental schools, compared with UCAS. Br Dent J. 2009 Nov 14;207(9):433-45.

[24] Partido BB, Stafford R. Association Between Emotional Intelligence and Academic Performance Among Dental Hygiene Students. J Dent Educ. 2018 Sep;82(9):974-979. doi: 10.21815/JDE.018.094. PMID: 30173194.

[25] Guang SA, Eltorai AEM, Durand WM, Daniels AH. Medical student burnout: Impact of the gap year in burnout prevention. Work. 2020;66(3):611-616.

[26] Sidiqi B, Gillespie EF, Wang C, Dawson M, Wu AJ. Mind the gap: an analysis of "gap year" prevalence, productivity, and perspectives among radiation oncology residency applicants. Int J Radiat Oncol Biol Phys. 2019 Jun 1;104(2):456-462.

[27] Schripsema NR, van Trigt AM, Borleffs JCC, Cohen-Schotanus J. Impact of vocational interests, previous academic experience, gender and age on Situational Judgement Test performance. Adv Health Sci Educ Theory Pract. 2017 May;22(2):521-532.

[28] Henderson MC, Kelly CJ, Griffin E, Hall TR, Jerant A, Peterson EM, Rainwater JA, Sousa FJ, Wofsy D, Franks P. Medical school applicant characteristics associated with performance in Multiple Mini-Interviews versus traditional interviews: A MultiInstitutional Study. Acad Med. 2018 Jul;93(7):1029-1034.

[29] Harris JA, Herzog C, Terán VG, Seymour B. The true cost of applying to dental school: Diversity in the dental profession. J Dent Educ. 2020;84:1330-1333.

[30] Quas JA, Dickerson KL, Matthew R, Harron C, Quas CM. Adversity, emotion recognition, and empathic concern in high-risk youth. PLoS One. 2017 Jul 24;12(7):e0181606.

[31] Russo-Netzer P, Moran G. Positive growth from adversity and beyond: Insights gained from cross-examination of clinical and nonclinical samples. Am J Orthopsychiatry. 2018;88(1):59-68. 
[32] Ballard RW, Hagan JL, Cheramie T. Relationship between hand-skill exercises and other admissions criteria and students' performance in dental school. J Dent Educ. 2015 May;79(5):557-62.

[33] Pau AK, Croucher R. Emotional intelligence and perceived stress in dental undergraduates. J Dent Educ. 2003 Sep;67(9):1023-8.

[34] Hannah A, Lim BT, Ayers KM. Emotional intelligence and clinical interview performance of dental students. J Dent Educ. 2009 Sep;73(9):1107-17. 